\title{
, \\ Kinetics Study of Hydrothermal Degradation of PET Waste into Useful Products
}

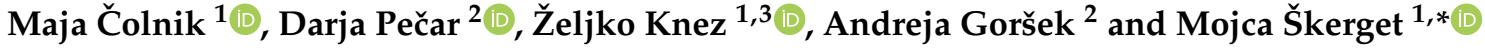 \\ 1 Laboratory for Separation Processes and Product Design, Faculty of Chemistry and Chemical Engineering, \\ University of Maribor, Smetanova 17, SI-2000 Maribor, Slovenia; maja.colnik@um.si (M.Č.); \\ zeljko.knez@um.si (Ž.K.) \\ 2 Laboratory for Process Systems Engineering and Sustainable Development, Faculty of Chemistry and \\ Chemical Engineering, University of Maribor, Smetanova 17, SI-2000 Maribor, Slovenia; \\ darja.pecar@um.si (D.P.); andreja.gorsek@um.si (A.G.) \\ 3 Department for Chemistry, Faculty of Medicine, University of Maribor, Taborska 8, SI-2000 Maribor, Slovenia \\ * Correspondence: mojca.skerget@um.si
}

check for updates

Citation: Čolnik, M.; Pečar, D.; Knez, Ž.; Goršek, A.; Škerget, M. Kinetics Study of Hydrothermal Degradation of PET Waste into Useful Products. Processes 2022, 10, 24. https:// doi.org/10.3390/pr10010024

Academic Editor: Aneta Magdziarz

Received: 6 December 2021

Accepted: 21 December 2021

Published: 23 December 2021

Publisher's Note: MDPI stays neutral with regard to jurisdictional claims in published maps and institutional affiliations.

Copyright: (C) 2021 by the authors. Licensee MDPI, Basel, Switzerland. This article is an open access article distributed under the terms and conditions of the Creative Commons Attribution (CC BY) license (https:// creativecommons.org/licenses/by/ $4.0 /)$

\begin{abstract}
Kinetics of hydrothermal degradation of colorless polyethylene terephthalate (PET) waste was studied at two temperatures $\left(300{ }^{\circ} \mathrm{C}\right.$ and $\left.350{ }^{\circ} \mathrm{C}\right)$ and reaction times from 1 to $240 \mathrm{~min}$. PET waste was decomposed in subcritical water (SubCW) by hydrolysis to terephthalic acid (TPA) and ethylene glycol (EG) as the main products. This was followed by further degradation of TPA to benzoic acid by decarboxylation and degradation of EG to acetaldehyde by a dehydration reaction. Furthermore, by-products such as isophthalic acid (IPA) and 1,4-dioxane were also detected in the reaction mixture. Taking into account these most represented products, a simplified kinetic model describing the degradation of PET has been developed, considering irreversible consecutive reactions that take place as parallel in reaction mixture. The reaction rate constants $\left(k_{1}-k_{6}\right)$ for the individual reactions were calculated and it was observed that all reactions follow first-order kinetics.
\end{abstract}

Keywords: PET waste; subcritical water; kinetics; degradation; TPA

\section{Introduction}

The global production of plastic materials is still growing and exceeded 367 million metric tons in 2020 [1], making the recycling of plastic waste an urgent global commitment. Polyethylene terephthalate (PET) is the third most widely used polymer [2] in the production of packaging after polyethylene (PE) and polypropylene (PP). The primary use of PET polymer is in the textile industry, although vast amounts of this material are used to make packaging in the food, medical and cosmetic industries. PET bottle is one of the most largely consumed plastic products [3]. PET bottles are durable, clear, light, inexpensive, heat-stable, and they are usually used for beverage and food applications [4]. The global production of PET bottles reached 13.1 million tons in 2020 [5]. PET is one of the main condensation polymers, which are known to be composed of different monomers. Specifically, PET can be synthesized by esterification of monomers of terephthalic acid (TPA) and ethylene glycol (EG) or by transesterification of dimethyl terephthalate (DMT) and EG [6]. Condensation polymers have ether, ester, or amide bonds, which can be depolymerized back to monomers by solvolysis (hydrolysis, alcoholysis) under mild conditions [7]. Even though PET can be mechanically recycled several times, a large amount of waste is still generated $[3,8]$. Above all, recycling problems occur when mixing PET bottles by color (the significant problem present the colorants and additives [9]) and with other plastic materials (the caps of PET bottles are usually made from polyolefins and have to be recycled separately) [3]. In addition, PET also can be recycled by pyrolysis. Pyrolysis is one of the most studied methods for the chemical recycling of different polymers including PET. Due to the possibility of obtaining valuable chemicals, liquid fuel and gas, this method has received increasing attention in recent years [10-13]. In general, a high temperature 
$\left(400-800{ }^{\circ} \mathrm{C}\right)$ is needed for complete degradation of PET waste. Pyrolysis of PET waste mainly produces a gas phase, where more than $45 \%$ of the PET material is degraded to $\mathrm{CO} / \mathrm{CO}_{2}$ and the light hydrocarbons (4 wt \%), where $2.8 \%$ corresponds to methane [10]. Furthermore, by pyrolysis, the residues of char decrease while the yield of gas products increases with increasing temperature and reaction time $[10,14,15]$.

Traditionally used plastic conversion methods, such as incineration and mechanical recycling, raise some environmental concerns and are not economically attractive. In recent years, the chemical recycling of waste using supercritical fluids (SCF) has become interesting due to several advantages. Processes using SCFs represent green technology that is easy to use and has other important advantages (reducing energy consumption and emissions into the environment). One promising media is water in subcritical (SubCW) and supercritical (SCW) state, which provides a strong oxidation environment and can degrade plastic and bio-waste and produce various high value-added products [16]. These processes, if carefully optimized, can produce fuels and even monomers that can be re-used to synthesize polymers, reducing the direct demand for fossil raw materials [7]. SubCW is often used for the processing and decomposition of biomass [16-18], and currently, it is also increasingly used for chemical recycling of polymers into monomers [7,19]. Although SubCW has many beneficial properties (compared to conventional hydrolysis media), on the other hand, much work remains to be done in order to understand the reaction pathways of polymers in this media. Understanding the hydrolysis process and the degradation mechanism is crucial for scaling up the recycling process to industrial level. Due to the complex composition and different reactivity of individual components contained in waste materials, the mechanisms of reactions and the influence of process parameters are still relatively unexplored. Recycled monomers and other low molecular weight compounds are an important category of secondary raw materials used in several promising industries such as chemistry, paint industry, textile industry, and pharmacy.

PET in SubCW decomposes into the major monomers TPA and EG and other secondary products [19-21]. TPA is an organic component usually produced by homogeneous oxidation of p-xylene in the liquid phase [22]. TPA is of great industrial importance as a raw material for various widely used plastics, such as PET, polybutyl terephthalate (PBT), and bioplastics, which have been in great demand recently [23]. TPA is an important chemical and it is also widely used in the pharmaceutical industry (raw material for certain drugs) [24], paints and coatings industry (as a carrier), in arms industry (TPA smoke-for grenade filler) [25], and in the manufacture of clothing and plastic bottles [26]. Production of purified TPA reached around 84 million metric tons in 2018 and forecasts indicate that it is expected to reach 107 million metric tons by 2023 [27]. Another important carboxylic acid formed during the degradation of PET in SubCW is benzoic acid [19,23]. Benzoic acid is currently produced by partial oxidation of toluene and oxygen in the presence of manganese naphthalenes or cobalt [28]. Benzoic acid is widely used in the food industry as an antimicrobial preservative in food and beverages, especially in carbonated drinks [28]. It has the strongest antibacterial action, which is a significant cause of food spoilage. It is used in the cosmetics and personal care industries [29]. Benzoic acid is also used as a precursor of other products such as plasticizers, fungal ointments for medical use, and as a calibrating substance for bomb calorimeters [30,31]. In 2020, the global production of benzoic acid amounted to 538,770 tons and it is expected to grow to 628,350 tons by 2026 [32]. Therefore, due to the increasing use of TPA and benzoic acid, the recovery of these organic compounds from waste is highly important.

In our previous work, it was found that SubCW can be used as an efficient medium for the hydrolysis of colored and colorless PET waste. A high yield of the desired TPA product (approximately 90\%) can be obtained under relatively mild hydrothermal conditions ( $300{ }^{\circ} \mathrm{C}, 95 \mathrm{bar}$, and $30 \mathrm{~min}$ ). Nevertheless, besides TPA and EG as primary products, isophthalic acid (IPA) and 1,4-dioxane, as well as secondary products such as acetaldehyde, and benzoic acid were also identified in the reaction mixture after degradation, which indicates further degradation of primary products [19]. 
Although many authors have studied the hydrothermal degradation of PET waste $[20,21,33]$ no data could be found in the literature dealing with decomposition kinetics. The aim of this work is to study the kinetics of hydrothermal degradation of colorless PET waste, to estimate kinetic data and to evaluate its degradation pathway.

\section{Materials and Methods}

\subsection{Materials}

TPA (99\%), IPA (99\%), 1,4-dioxane (99.8\%), and acetaldehyde (99.5\%) were supplied by Sigma-Aldrich (Steinheim, Germany), while benzoic acid was provided by Merck (Darmstadt, Germany). Nitrogen $\left(\mathrm{N}_{2}\right)(99.5 \%)$ as an inert gas was supplied by Messer (Ruše, Slovenia). Acetonitrile (ACN) (99.9\%), methanol (99.9\%), and trifluoroacetic acid (TFA) were obtained from Fisher Scientific (Loughborough, LE, UK), J.T. Baker (Deventer, The Netherlands), and Sigma-Aldrich. Sodium hydroxide $(\mathrm{NaOH})$ and hydrochloric acid $(\mathrm{HCl})$ were supplied by Sigma-Aldrich. All standards and solvents were of analytical grades.

\subsection{Sample Preparation}

PET colorless beverage bottles were collected, and material was prepared for experiments. First, the caps and the labels from the bottles were removed and then the material was cleaned and cut into small equal parts $(1 \times 1 \mathrm{~cm})$.

\subsection{Elemental Analysis}

The colorless PET bottle waste sample was also characterized with the Perkin Elmer 2400 Series II system analyzer. The content of the main elements (carbon, hydrogen, nitrogen, and sulfur) was determined (Table 1), while oxygen was calculated by the mass balance.

Table 1. Ultimate analysis of colorless PET waste bottles.

\begin{tabular}{cc}
\hline Element & $\mathbf{w t} \%$ \\
\hline $\mathrm{C}$ & 62.1 \\
$\mathrm{H}$ & 4.20 \\
$\mathrm{~N}$ & 0.14 \\
$\mathrm{~S}$ & 0.32 \\
O by difference $(\mathrm{wt} \%)$ & 33.24 \\
\hline
\end{tabular}

\subsection{FTIR Analysis}

Fourier transform infrared (FTIR) spectroscopy of colorless PET waste, recycled TPA, and standard of TPA were performed on an IRAffinity-1 spectrophotometer equipped with an attenuated total reflectance cell (ATR). The spectra of individual samples were recorded at wavelengths from 4000 to $400 \mathrm{~nm}$ against the air as the background at a resolution of $4 \mathrm{~cm}^{-1}$ and a total of 20 co-added scans. After all, the data were analyzed with high-performance IRsolution software.

\subsection{Subcritical Water Treatment of PET}

The decomposition of colorless PET waste in SubCW (material/water ratio (1/10)) was performed in a $75 \mathrm{~mL}$ high-temperature and high-pressure batch reactor (Parr Instruments, Moline, IL, USA). A detailed description of the experimental system (Figure 1) and procedure can be found in the literature [19]. The degradation reactions of PET were carried out at temperatures 300 and $350{ }^{\circ} \mathrm{C}$ and reaction time between 1 and $240 \mathrm{~min}$. The mixture of PET and water in a weight ratio $1 / 10$ was loaded into the batch reactor at room temperature. Before hydrolysis of PET waste, the reactor was flushed several times with nitrogen and then this gas was used to set the initial pressure in the reactor to 20 bar. The reactor was heated by a high-power heating collar controlled by a temperature controller. At the temperature of 300 and $350{ }^{\circ} \mathrm{C}$, the pressure in the reactor was $89 \pm 2$ bar and $168 \pm 2$ bar, respectively. During the degradation of colorless PET waste, 
the reaction mixture was stirred constantly at $1000 \mathrm{~min}^{-1}$. After a specific time, the reactor was immediately quenched with cold water, then the gas was released from the system and the products from the reactor were collected. The post-reaction mixture contained liquid and solid products. First, $1 \mathrm{~mL}$ of the aqueous post-reaction mixture was separated and filtered through a $45 \mu \mathrm{m}$ filter and the filtrate was stored for further HPLC analysis. All remaining reaction mixture was treated with $4 \mathrm{M} \mathrm{NaOH}$ to form sodium salt of TPA, that is soluble in water and then filtered to remove any undegraded PET residues. Finally, TPA was precipitated with 1.5 M HCL. After filtration and drying, the concentration of formed TPA and undegraded PET waste residues in the post-reaction mixture was calculated by the following Equations (1) and (2):

$$
\begin{aligned}
& c_{\mathrm{TPA}}=m_{\mathrm{TPA}} / V_{\mathrm{H}_{2} \mathrm{O}} \\
& c_{\mathrm{PET}}=m_{\mathrm{PET}} / V_{\mathrm{H}_{2} \mathrm{O}}
\end{aligned}
$$

where: $c_{\mathrm{TPA}}$ is the concentration of TPA, $c_{\mathrm{PET}}$ is the concentration of PET, $m_{\mathrm{TPA}}$ is the mass of precipitated TPA, $m_{\text {PET }}$ is the mass of unreacted colorless PET waste and $V_{\mathrm{H}_{2} \mathrm{O}}$ is the initial volume of distilled water before hydrolysis.

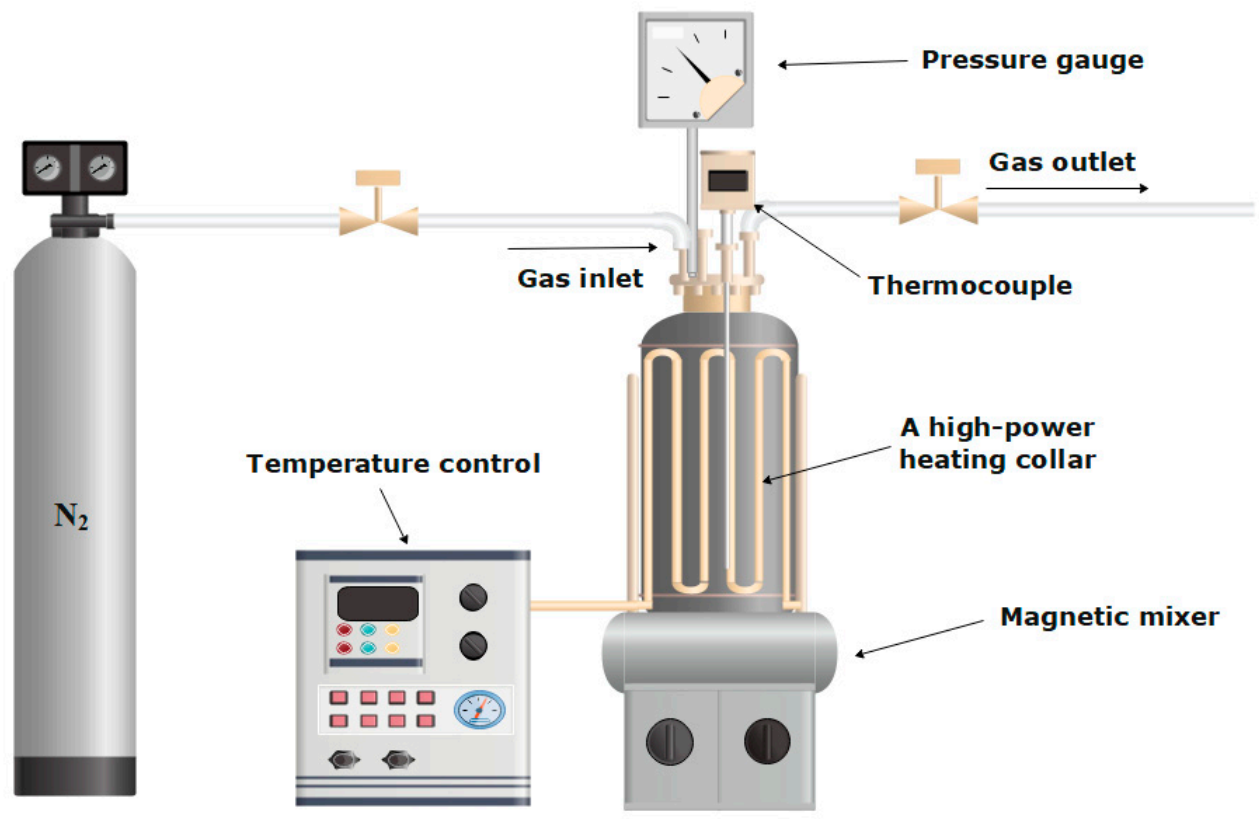

Figure 1. A batch reactor system of SubCW treatment.

\subsection{HPLC Method}

The concentrations of products in the aqueous phase after hydrolysis of colorless PET waste were determined using an HPLC system (model 1100, Agilent technology, Waldbronn, Germany) with an UV-Vis detector [19]. The column was an Agilent ZORBAX Eclipse XDB C18 column $(4.6 \times 150 \mathrm{~mm}, 3.5 \mu \mathrm{m}$ particle diameter $)$ and the temperature of the column was $30{ }^{\circ} \mathrm{C}$. Mobile phase A was Milli-Q water with $0.1 \% \mathrm{TFA} / \mathrm{ACN}$ in a ratio of $60 / 40$, while mobile phase B was Milli-Q water with $0.1 \%$ TFA/ACN in a ratio of $90 / 10$. The gradient was: $0 \mathrm{~min} 90 \% \mathrm{~B}, 3 \mathrm{~min} 70 \% \mathrm{~B}, 8 \mathrm{~min} 60 \% \mathrm{~B}$ at $242 \mathrm{~nm}$. The volume of initiated samples was $20 \mu \mathrm{L}$, while the flow rate was $1 \mathrm{~mL} / \mathrm{min}$. The identification and the quantification of the resulting products were performed using calibration curves of individual standards [19].

\section{Results and Discussion}

\subsection{Degradation of Colorless PET Waste in SubCW}

The results of our previous work [19] and data from the literature [20,21] show that the depolymerization of PET starts at $250{ }^{\circ} \mathrm{C}$ at a short reaction time, where with the 
reaction of hydrolysis, the main monomers, TPA and EG, are formed. At the same time, some small amounts of unreacted PET, oligomers, IPA, and 1,4-dioxane were also present in the post-reaction mixture $[19,21]$. With further increase in temperature to $300^{\circ} \mathrm{C}$, all PET waste degraded in the SubCW and gave the highest yield of TPA and EG [19,21]. At higher temperatures, the concentration of EG in the reaction mixture decreased with increasing temperature and time [21] and at the same time, acetaldehyde, diethylene glycol, and triethylene glycol were formed from EG via dehydration and dimerization reactions, respectively $[19,21]$. Similarly, the concentration of TPA started to decrease at $300{ }^{\circ} \mathrm{C}$ with the extension of reaction time ( $\left.<30 \mathrm{~min}\right)$, and benzoic acid was formed due to decarboxylation reaction, where $\mathrm{CO}_{2}$ [19] was eliminated from TPA molecules (Figure 2).

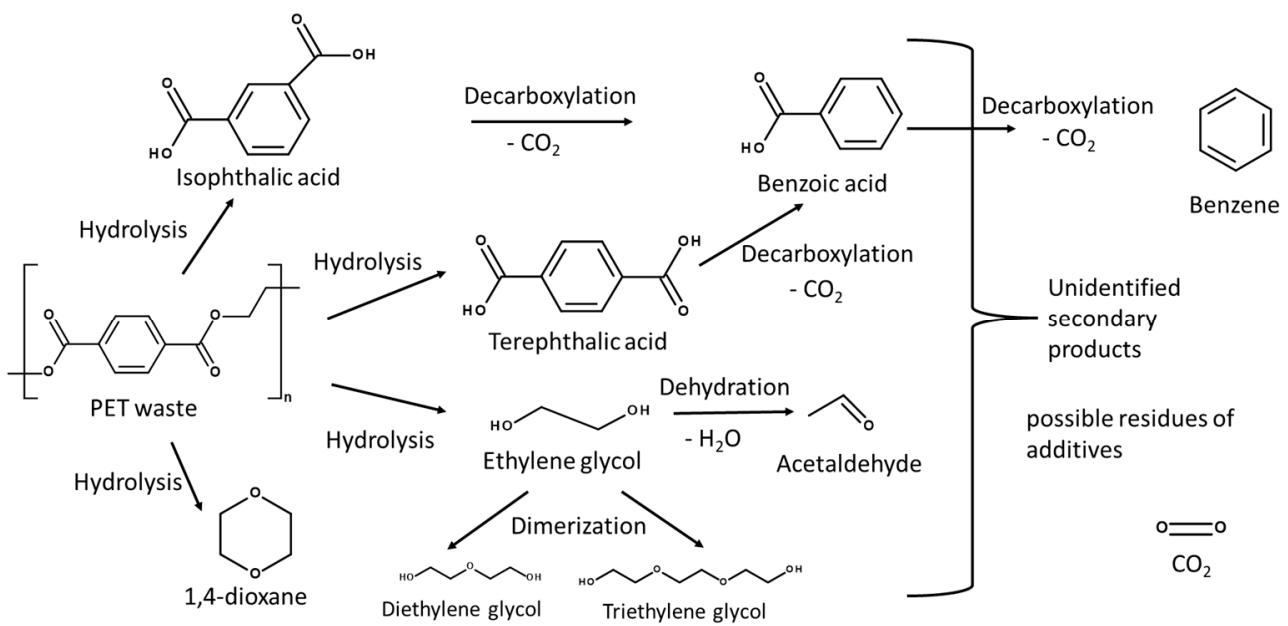

Figure 2. Reaction pathway of PET waste in SubCW.

To study the kinetics of PET degradation into valuable products, in the present work, colorless PET waste plastic was degraded in SubCW at temperatures of $300{ }^{\circ} \mathrm{C}$ and $350{ }^{\circ} \mathrm{C}$ and a reaction time of up to $240 \mathrm{~min}$. The focus was on the most represented components in the aqueous phase. The concentration ( $g_{\text {product }} / \mathrm{g}_{\mathrm{PET}}$ ) of main products, by-products, and secondary products are presented in Table 2.

Table 2. Concentration of degradation products ( $g_{\text {component }} / g_{\text {material }}$ ) of colorless PET waste in SubCW.

\begin{tabular}{|c|c|c|c|c|c|c|c|c|c|c|c|c|}
\hline \multirow[t]{2}{*}{$t^{1} \min$} & \multicolumn{2}{|c|}{$\begin{array}{c}c_{\text {(TPA) }} \\
\mathrm{g}_{\text {TPA }} / g_{\text {PET }}\end{array}$} & \multicolumn{2}{|c|}{$\begin{array}{c}c_{\text {(benzoic acid) }} \\
\mathrm{g}_{\text {benzoic acid }} / \mathrm{g}_{\text {PET }}\end{array}$} & \multicolumn{2}{|c|}{$\begin{array}{c}c_{(1,4-d i o x a n e)} \\
\mathrm{g}_{1,4-\text { dioxane }} / \mathrm{g}_{\text {PET }}\end{array}$} & \multicolumn{2}{|c|}{$\begin{array}{c}c_{(\mathrm{EG})} \\
\mathrm{g}_{\mathrm{EG}} / \mathrm{g}_{\mathrm{PET}}\end{array}$} & \multicolumn{2}{|c|}{$\begin{array}{c}c_{\text {(acetaldehyde) }} \\
\text { gacetaldehyde } / g_{\text {PET }}\end{array}$} & \multicolumn{2}{|c|}{$\begin{array}{c}c_{\text {(IPA) }} \\
\mathrm{g}_{\text {IPA }} / \mathrm{g}_{\text {PET }}\end{array}$} \\
\hline & $300^{\circ} \mathrm{C}$ & $350^{\circ} \mathrm{C}$ & $300^{\circ} \mathrm{C}$ & $350^{\circ} \mathrm{C}$ & $300{ }^{\circ} \mathrm{C}$ & $350{ }^{\circ} \mathrm{C}$ & $300^{\circ} \mathrm{C}$ & $350{ }^{\circ} \mathrm{C}$ & $300{ }^{\circ} \mathrm{C}$ & $350{ }^{\circ} \mathrm{C}$ & $300{ }^{\circ} \mathrm{C}$ & $350{ }^{\circ} \mathrm{C}$ \\
\hline 1 & 0.73 & 0.71 & 0 & 0.0014 & 0.0075 & 0.0076 & 0.112 & 0.140 & 0.0009 & 0.0586 & 0.0021 & 0.0035 \\
\hline 10 & 0.74 & 0.72 & 0 & 0.0033 & 0.0074 & 0.0075 & 0.224 & 0.162 & 0.0024 & 0.0831 & 0.0030 & 0.0043 \\
\hline 30 & 0.76 & 0.69 & 0.0003 & 0.0063 & 0.0072 & 0.0078 & 0.193 & 0.125 & 0.0123 & 0.1405 & 0.0030 & 0.0049 \\
\hline 60 & 0.75 & 0.64 & 0.0016 & 0.0425 & 0.0544 & 0.0156 & 0.129 & 0.086 & 0.0288 & 0.1806 & 0.0173 & 0.0145 \\
\hline 120 & 0.73 & 0.61 & 0.0027 & 0.0502 & 0.0400 & 0.0031 & 0.064 & 0.020 & 0.0942 & 0.2689 & 0.0188 & 0.0101 \\
\hline 180 & 0.70 & 0.56 & 0.0051 & 0.0592 & 0.0498 & 0.0013 & 0.016 & 0 & 0.1150 & 0.2753 & 0.0186 & 0.0118 \\
\hline 240 & 0.68 & 0.44 & 0.0088 & 0.0691 & 0.0239 & 0.0004 & 0 & 0 & 0.1200 & 0.2641 & 0.0184 & 0.0121 \\
\hline
\end{tabular}

${ }^{1} t$ is the reaction time at constant $T$ and $P$ (heating time not included).

It was found that all PET waste has decomposed already during the heating period to the desired temperature (12 $\mathrm{min})$, and the main products were formed. The data in Table 2 show that the highest concentration of main products was achieved at $300{ }^{\circ} \mathrm{C}$, namely for EG $\left(0.22 \mathrm{~g}_{\mathrm{EG}} / \mathrm{g}_{\mathrm{PET}}\right)$ at $10 \mathrm{~min}$ and for TPA $\left(0.76 \mathrm{~g}_{\mathrm{TPA}} / \mathrm{g}_{\mathrm{PET}}\right)$ at $30 \mathrm{~min}$. The maximum concentrations of by-products (IPA and 1,4-dioxane) were also detected at the reaction temperature of $300{ }^{\circ} \mathrm{C}$ when the reaction time increased to $60 \mathrm{~min}$ for 1,4-dioxane and to $120 \mathrm{~min}$ for IPA. The concentrations of products were $0.05 \mathrm{~g}_{1,4 \text {-dioxan }} / \mathrm{g}_{\mathrm{PET}}$ and $0.018 \mathrm{~g}_{\mathrm{IPA}} / \mathrm{g}_{\mathrm{PET}}$. The 
secondary products (acetaldehyde and benzoic acid) were formed with hydrothermal degradation of the main products. It was found that the concentrations of these secondary products increase with increasing reaction temperature to $350{ }^{\circ} \mathrm{C}$ and with increasing reaction time. The highest concentrations of benzoic acid $\left(0.07 \mathrm{~g}\right.$ benzoic acid $\left./ \mathrm{g}_{\mathrm{PET}}\right)$ and acetaldehyde $\left(0.27\right.$ gacetaldehyde $\left./ \mathrm{g}_{\text {PET }}\right)$ were detected at $350{ }^{\circ} \mathrm{C}$ and reaction time of $240 \mathrm{~min}$ and $180 \mathrm{~min}$, respectively. At these conditions, new unidentified products in the aqueous phase were also observed (e.g., possible residues of additives). Moreover, it was assumed that while benzoic acid is formed, part of the benzoic acid is simultaneously further degraded by the decarboxylation reaction and causes the formation of a new product-benzene [34].

In the following, based on our research and data from the literature $[19,21,34]$, the possible degradation mechanisms of PET waste in SubCW is presented in Figure 2.

\subsection{FTIR Analysis of Colorless PET Waste and Recycled TPA}

The FTIR technique was used to identify the main functional groups present in the colorless PET waste before hydrolysis and in the resulting recycled TPAs after SubCW treatment. The spectrum of the colorless PET waste sample (Figure 3) contained an absorption band at $3432 \mathrm{~cm}^{-1}$ (OH group), at $3100-2800 \mathrm{~cm}^{-1}$ (aromatic and aliphatic $\mathrm{C}-\mathrm{H}$ stretch), at $1720 \mathrm{~cm}^{-1}$ (ester carbonyl $\mathrm{C}=\mathrm{O}$ stretch), and at $1453-1342 \mathrm{~cm}^{-1}$ (bending and wagging vibrational modes of the $\mathrm{EG}$ segment). The main observation of the absorption bands at $1240 \mathrm{~cm}^{-1}$ and $1124 \mathrm{~cm}^{-1}$ confirmed the terephthalate group $\left(\mathrm{OOCC}_{6} \mathrm{H}_{4}-\mathrm{COO}\right)$. The absorption bands were consistent with previous works [35-37].

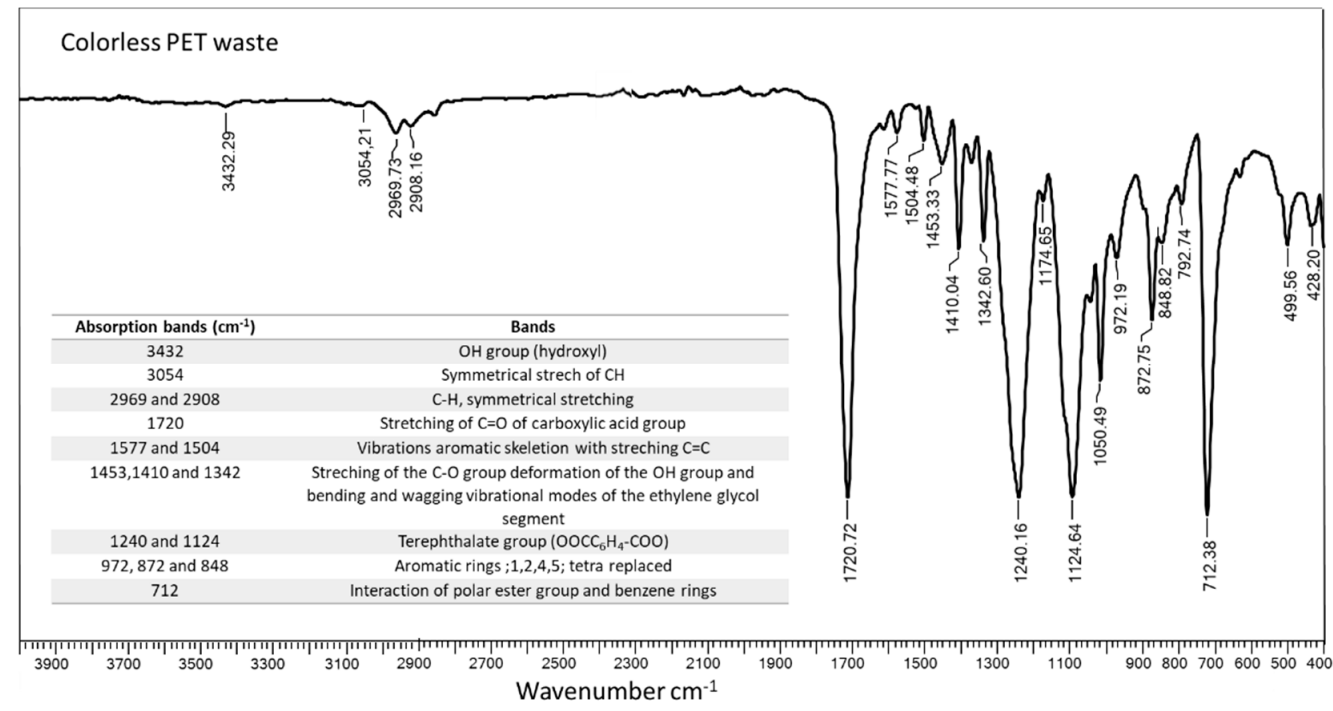

Figure 3. FTIR spectra of colorless PET waste before SubCW treatment.

FTIR analysis of a solid product obtained after hydrothermal degradation of colorless PET waste confirmed that the product contains main monomer TPA of high purity. According to Figure 4, recycled TPA presents the same characteristic absorption bands as the standard of TPA. The main IR bands of recycled TPA and TPA standard are shown at $3300-2500 \mathrm{~cm}^{-1}\left(\mathrm{O}-\mathrm{H}\right.$ stretch), at $1683 \mathrm{~cm}^{-1}$ (C=O stretch), at $1425 \mathrm{~cm}^{-1}(\mathrm{O}-\mathrm{H}$ bend), at $1283 \mathrm{~cm}^{-1}$ (C-O stretch), and at $948 \mathrm{~cm}^{-1}$ (O-H bend). Similar results of the functional groups of TPA have been reported previously $[19,20]$. 


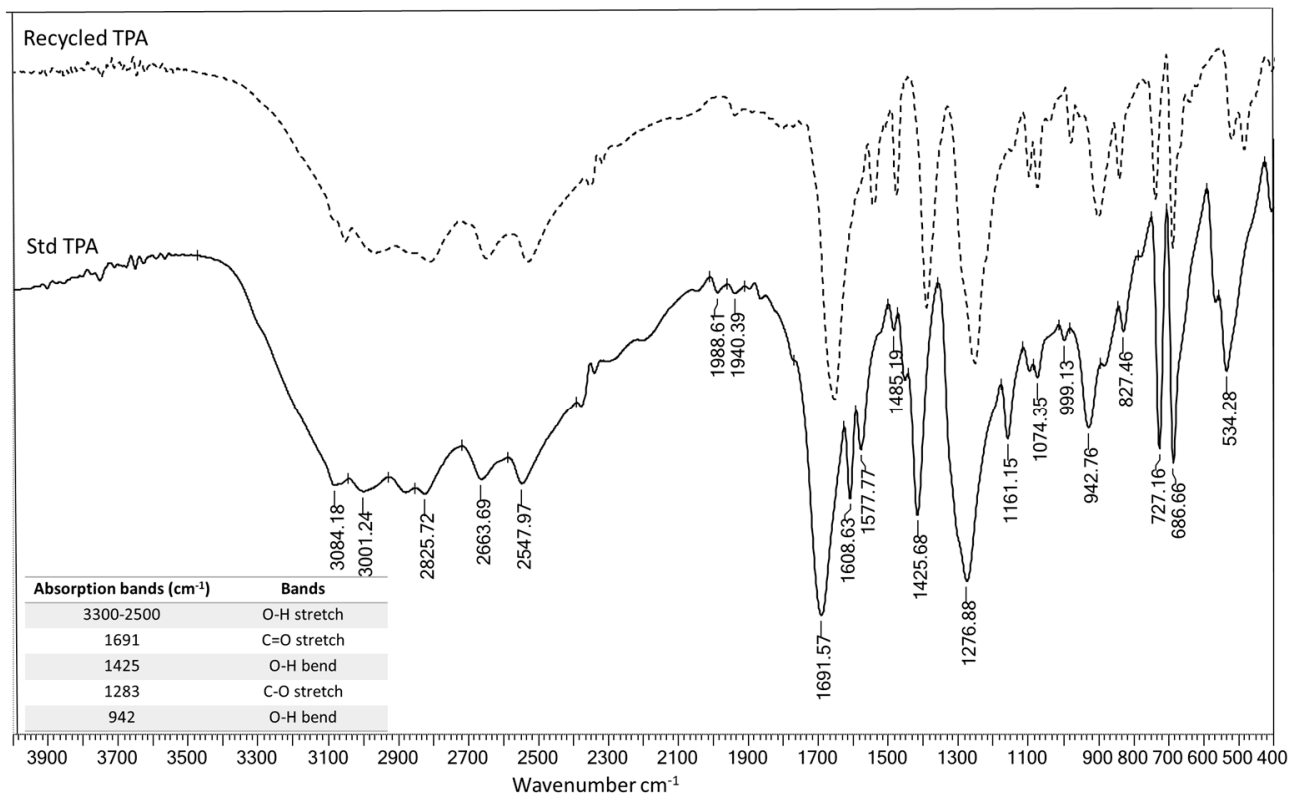

Figure 4. FTIR spectra of TPA standard and recycled TPA after hydrothermal degradation of colorless PET waste at the temperature of $350{ }^{\circ} \mathrm{C}$ and $120 \mathrm{~min}$.

\subsection{Kinetics of Hydrothermal Degradation of Colorless PET Waste}

Due to the fact that PET waste already completely decomposes during the heating period to the desired temperature (12 $\mathrm{min})$, the reaction kinetics during the heating period were also studied and degradation products were analyzed and considered for the kinetic modeling. The results show that the hydrothermal decomposition of colorless PET waste can be represented by a kinetic scheme for irreversible reactions, as presented in Figure 5. The method used in this study follows the concentration profile of PET waste (A), major PET hydrolysis products TPA (B) and EG (E), PET degradation by-products 1,4-dioxane (D) and IPA (G), and secondary products that are formed from major hydrolysis products, i.e., benzoic acid $(\mathrm{C})$ and acetaldehyde $(\mathrm{F})$. By prolonging the reaction time, $\mathrm{CO}_{2}$ is cleaved from the TPA molecule [19] by decarboxylation to form the secondary product benzoic acid (C), while acetaldehyde (F) is most likely formed by dehydration of EG (Figure 6). As mentioned above, the proposed kinetic model representing the decomposition of colorless PET waste has been simplified; specifically, it does not consider unknown components that appear in the aqueous phase in the initial stage of PET degradation and most likely represent oligomers of PET polymer [21], as well as decomposition products of additives present in the waste PET plastic $[7,38]$.

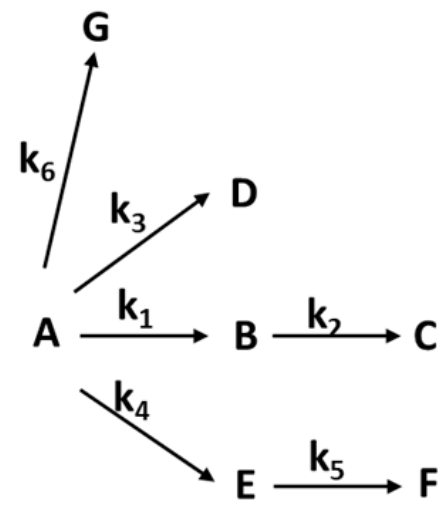

Figure 5. Scheme of proposed kinetics model of colorless PET waste degradation in SubCW. PET (A), TPA (B), benzoic acid (C), 1,4-dioxane (D), EG (E), acetaldehyde (F), IPA (G). 

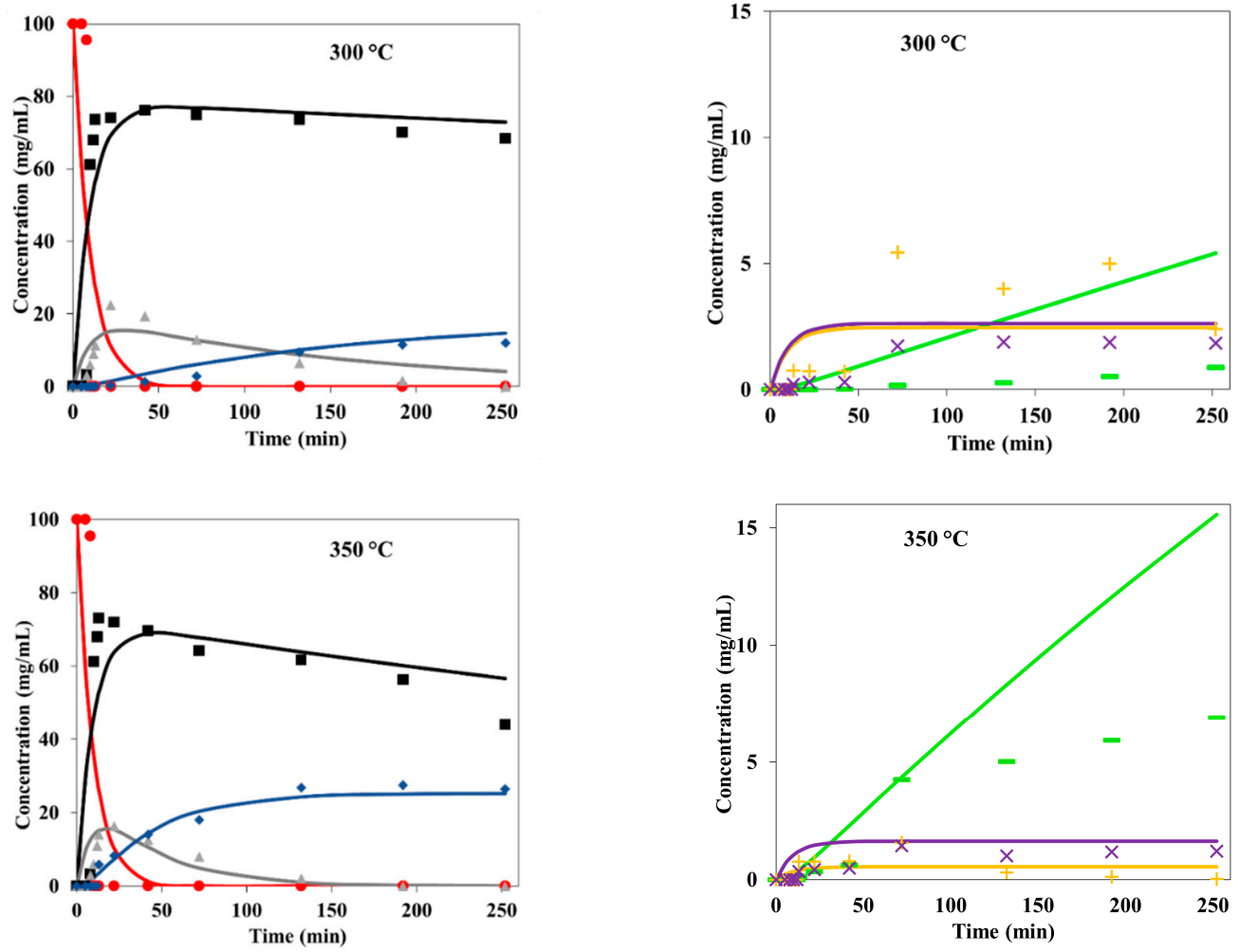

- PET —TPA - Acetaldehyde $\triangle$ EG -Benzioc acid +1,4-dioxane XIPA

Figure 6. Colorless PET waste and its degradation products: TPA, EG, benzoic acid, 1,4-dioxane, acetaldehyde, and IPA at temperatures of 300 and $350{ }^{\circ} \mathrm{C}$ during heating period (first $12 \mathrm{~min}$ ) and reaction at constant conditions. The symbols represent experimental measurements, while the curves represent a kinetic model.

For the kinetic modeling of the decomposition of colorless PET waste, it was assumed that the hydrolysis of PET waste follows first-order kinetics because the difference between the experimental and model data was the lowest compared to zero- and second-order kinetics. The corresponding reaction rates for all six reactions were described by the following differential Equations (3)-(9):

$$
\begin{gathered}
-\frac{\mathrm{d} c_{\text {PET waste }}}{\mathrm{d} t}=\left(k_{1}+k_{3}+k_{4}+k_{6}\right) c_{\text {PET waste }} \\
\frac{\mathrm{d} c_{1,4-d i o x a n e}}{\mathrm{~d} t}=k_{3} c_{\text {PET waste }} \\
\frac{\mathrm{d} c_{\text {TPA }}}{\mathrm{d} t}=k_{1} c_{\text {PET waste }}-k_{2} c_{\text {TPA }} \\
\frac{\mathrm{d} c_{\text {benzoic acid }}}{\mathrm{d} t}=k_{2} c_{\text {TPA }} \\
\frac{\mathrm{d} c_{E G}}{\mathrm{~d} t}=k_{4} c_{\text {PET waste }}-k_{5} c_{\text {EG }} \\
\frac{\mathrm{d} c_{\text {acetaldehyde }}}{\mathrm{d} t}=k_{5} c_{\text {EG }} \\
\frac{\mathrm{d} c_{\text {IPA }}}{\mathrm{d} t}=k_{6} c_{\text {PET waste }}
\end{gathered}
$$

where: $c_{\text {PET waste }}$ is the concentration of PET waste, $c_{\mathrm{TPA}}$ the concentration of TPA, $c_{\text {benzioc acid }}$ the concentration of benzoic acid, $c_{1,4-d i o x a n e}$ the concentration of 1,4-dioxane, $c_{\mathrm{EG}}$ the con- 
centration of EG, $c_{\text {acetaldehyde }}$ the concentration of acetaldehyde and $c_{\text {IPA }}$ the concentration of IPA; $k_{1}, k_{2}, k_{3}, k_{4}, k_{5}$ in $k_{6}$ are the reaction rate constants of individual reactions, and $t$ is the reaction time.

Differential Equations (3)-(9) were numerically integrated using Scientist (MicroMath) software, minimizing the objective function represented by the sum of the square differences between the experimental and calculated concentrations. The calculated reaction rate constants are shown in Table 3. The standard deviation of constants $k_{2}, k_{3}$, and $k_{6}$ is significant due to the scattering of experimental data.

Table 3. Reaction rate constants for irreversible sequential reactions of PET waste in SubCW at different temperatures.

\begin{tabular}{ccc}
\hline $\boldsymbol{k}\left(\mathbf{m i n}^{-1}\right)$ & $\mathbf{3 0 0}{ }^{\circ} \mathbf{C}$ & $\mathbf{3 5 0}{ }^{\circ} \mathbf{C}$ \\
\hline$k_{1}\left(\min ^{-1}\right)$ & $0.07804 \pm 0.00882$ & $0.07472 \pm 0.00896$ \\
$k_{2}\left(\min ^{-1}\right)$ & $0.00030 \pm 0.00036$ & $0.00101 \pm 0.00044$ \\
$k_{3}\left(\min ^{-1}\right)$ & $0.00245 \pm 0.00422$ & $0.00057 \pm 0.00444$ \\
$k_{4}\left(\min ^{-1}\right)$ & $0.01879 \pm 0.00477$ & $0.02615 \pm 0.00545$ \\
$k_{5}\left(\min ^{-1}\right)$ & $0.00804 \pm 0.00458$ & $0.02697 \pm 0.01590$ \\
$k_{6}\left(\min ^{-1}\right)$ & $0.00261 \pm 0.00376$ & $0.00169 \pm 0.00392$ \\
\hline
\end{tabular}

Figure 6 shows the distribution of the PET waste and its decomposition products in dependence of the reaction time and temperature, where first 12 min present the heating period, followed by reaction at constant conditions, and comparison between experimental and model data. Results show that the concentration of PET waste significantly decreases with increasing temperature and reaction time, while TPA and EG concentrations first increase and reach the maximum at $300{ }^{\circ} \mathrm{C}$ and $42 \mathrm{~min}$ for TPA $(76.12 \mathrm{mg} / \mathrm{mL})$ and $22 \mathrm{~min}$ for EG (22.4 mg/mL). After that, the concentrations of TPA and EG start to decline. During the hydrolytic degradation reaction at $300{ }^{\circ} \mathrm{C}$ and shorter reaction times (13 min), two new by-products, i.e., 1,4-dioxane and IPA start to form, with concentrations of $0.2 \mathrm{mg} / \mathrm{mL}$ and $0.75 \mathrm{mg} / \mathrm{mL}$, respectively. IPA is an isomer of TPA and is often added in the production of PET materials [39], while 1,4-dioxane is a cyclic ether formed as a by-product in the PET production process [40]. Corresponding reaction rate constants $k_{3}$ and $k_{6}$ at $300{ }^{\circ} \mathrm{C}$ are similar and are higher as at $350{ }^{\circ} \mathrm{C}$, which indicates faster degradation of both compounds at higher temperature. By further prolonging the reaction time at $300{ }^{\circ} \mathrm{C}$, the formation of benzoic acid is observed in the post-reaction mixture at a reaction time of 42 minutes and its concentration increases with time due to the decarboxylation of $\mathrm{CO}_{2}$ from the TPA molecule, which was also confirmed by gas analysis in our previous study [19]. The highest concentration of benzoic acid is achieved at a temperature of $350{ }^{\circ} \mathrm{C}$ and reaction time of $240 \mathrm{~min}$ and it is $6.91 \mathrm{mg} / \mathrm{mL}$. Further, Figure 6 also shows that at higher temperature $\left(350{ }^{\circ} \mathrm{C}\right)$ the concentrations of TPA and EG decrease faster with prolongation of the reaction time as at $300{ }^{\circ} \mathrm{C}$ and, therefore, reaction rate constants $k_{2}$ and $k_{5}$, indicating the rate of formation of their degradation products benzoic acid and acetaldehyde, are higher at $350{ }^{\circ} \mathrm{C}$. The reaction rate constant $\left(k_{1}\right)$ for TPA is similar at both temperatures.

It can also be seen from Figure 6 that at both temperatures, the concentrations of products IPA, 1,4-dioxane, and acetaldehyde first increase and then begin to decline after a certain time.

The significant differences between the experimental and model results for decomposition of primary and secondary products were assigned to the formation of unidentified products. It would be expected that with further degradation of TPA, the concentration of benzoic acid would increase even more with the prolongation of the reaction time at $350{ }^{\circ} \mathrm{C}$. However, HPLC analysis of the aqueous solution containing degradation products showed that unknown (new unidentified) degradation products began to form, which could be attributed to the degradation of benzoic acid. Lindquist and Yang [34] found that benzoic acid degraded in SubCW at $350{ }^{\circ} \mathrm{C}$ as the reaction time increased (more than $25 \%$ of benzoic acid was degraded by a reaction time of $240 \mathrm{~min}$ ) as $\mathrm{CO}_{2}$ was cleaved from the benzoic 
acid molecule, thereby causing the formation of a new benzene product [34], which was not analyzed in these study.

\section{Conclusions}

Kinetic study of hydrothermal degradation of PET waste to major monomers TPA and EG, and secondary products (IPA, 1-4 dioxane, acetaldehyde and benzoic acid) shows that all individual reactions follow first-order kinetics. The reaction rate constant of formation of TPA $\left(k_{1}\right)$ was not significantly different at both temperatures, while the reaction rate constants $k_{3}$, and $k_{6}$, indicating formation of IPA and 1,4-dioxane, were higher at $300{ }^{\circ} \mathrm{C}$ than at $350{ }^{\circ} \mathrm{C}$, which indicates that at higher temperatures, these compounds undergo faster further degradation. Conversely, the reaction rate constants $k_{2}$ and $k_{5}$, indicating formation of benzoic acid and acetaldehyde, were higher at $350{ }^{\circ} \mathrm{C}$ as at $300{ }^{\circ} \mathrm{C}$, which indicates a higher degradation rate of TPA and EG at higher temperature. The maximum concentration of TPA in the aqueous phase was determined to be $300{ }^{\circ} \mathrm{C}$ and the reaction time (heating period not included) was $30 \mathrm{~min}\left(0.76 \mathrm{~g}_{\mathrm{TPA}} / \mathrm{g}_{\mathrm{PET}}\right)$, while the highest concentration of EG was achieved at $300^{\circ} \mathrm{C}$ and $10 \mathrm{~min}$, and was $0.22 \mathrm{gEG} / \mathrm{g}_{\mathrm{PET}}$. The concentration of benzoic acid, a degradation product of TPA, increased with increasing temperature and time and the highest concentration was detected at $350{ }^{\circ} \mathrm{C}$ and $240 \mathrm{~min}$ and was 0.69 g benzoic acid $/ \mathrm{g}_{\text {PET }}$. Similar was observed for acetaldehyde, a degradation product of EG, where the highest concentration was achieved at $350{ }^{\circ} \mathrm{C}$ and $180 \mathrm{~min}$ and it was $0.27 \mathrm{~g}_{\text {acetaldehyde }} / \mathrm{g}_{\mathrm{PET}}$. The concentrations of 1,4-dioxane $\left(0.05 \mathrm{~g}_{1,4 \text {-dioxane }} / \mathrm{g}_{\mathrm{PET}}\right)$ and IPA $\left(0.018 \mathrm{~g}_{\mathrm{IPA}} / \mathrm{g}_{\mathrm{PET}}\right)$ were the highest at temperature of $300{ }^{\circ} \mathrm{C}$ and reaction time of $60 \mathrm{~min}$ and $120 \mathrm{~min}$, respectively.

Author Contributions: M.Č.: Formal analysis, Investigation, Conceptualization, Writing-original draft, Writing—review and editing. D.P.: Data curation, Formal analysis, Software, Ž.K.: Funding acquisition, Supervision, A.G. Supervision, M.Š.: Investigation, Conceptualization, Writing-review and editing, Supervision. All authors have read and agreed to the published version of the manuscript.

Funding: Special thanks to the Slovenian Research Agency (ARRS) for financial support of research program groups P2-0046: Separation processes and product design and P2-0032: Process systems engineering and sustainable development.

Informed Consent Statement: Not applicable.

Data Availability Statement: Not applicable.

Conflicts of Interest: The authors declare no conflict of interest.

\section{References}

1. Global Plastic Production 1950-2020. Available online: https://www.statista.com/statistics/282732/global-production-ofplastics-since-1950/ (accessed on 20 September 2021).

2. Allaf, R.M.; Albarahmieh, E.; Futian, M. Preparation of Sawdust-Filled Recycled-PET Composites via Solid-State Compounding. Processes 2020, 8, 100. [CrossRef]

3. Gopalakrishna, K.G.; Reddy, N. 2-Regulations on Recycling PET Bottles. In Recycling of Polyethylene Terephthalate Bottles; Thomas, S., Rane, A., Kanny, K., Abitha, V.K., Thomas, M.G., Eds.; William Andrew Publishing: Norwich, NY, USA, 2019; pp. 23-35, ISBN 978-0-12-811361-5.

4. Karayannidis, G.P.; Chatziavgoustis, A.P.; Achilias, D.S. Poly (Ethylene Terephthalate) Recycling and Recovery of Pure Terephthalic Acid by Alkaline Hydrolysis. Adv. Polym. Technol. 2002, 21, 250-259. [CrossRef]

5. PET Bottle Market: Global Industry Trends, Share, Size, Growth, Opportunity and Forecast 2021-2026. Available online: https://www.researchandmarkets.com/reports/5264119/pet-bottle-market-global-industry-trends-share (accessed on 26 August 2021).

6. Mandal, S.; Dey, A. 1-PET Chemistry. In Recycling of Polyethylene Terephthalate Bottles; Thomas, S., Rane, A., Kanny, K., VK, A., Thomas, M.G., Eds.; William Andrew Publishing: Norwich, NY, USA, 2019; pp. 1-22. ISBN 978-0-12-811361-5.

7. Queiroz, A.; Pedroso, G.B.; Kuriyama, S.N.; Fidalgo-Neto, A.A. Subcritical and Supercritical Water for Chemical Recycling of Plastic Waste. Curr. Opin. Green Sustain. Chem. 2020, 25, 100364. [CrossRef]

8. Chirayil, C.J.; Mishra, R.K.; Thomas, S. 3-Materials Recovery, Direct Reuse and Incineration of PET Bottles. In Recycling of Polyethylene Terephthalate Bottles; Thomas, S., Rane, A., Kanny, K., VK, A., Thomas, M.G., Eds.; William Andrew Publishing: Norwich, NY, USA, 2019; pp. 37-60, ISBN 978-0-12-811361-5. 
9. Hahladakis, J.N.; Velis, C.A.; Weber, R.; Iacovidou, E.; Purnell, P. An Overview of Chemical Additives Present in Plastics: Migration, Release, Fate and Environmental Impact during Their Use, Disposal and Recycling. J. Hazard. Mater. 2018, 344, 179-199. [CrossRef] [PubMed]

10. Martín-Gullón, I.; Esperanza, M.; Font, R. Kinetic Model for the Pyrolysis and Combustion of Poly-(Ethylene Terephthalate) (PET). J. Anal. Appl. Pyrolysis 2001, 58-59, 635-650. [CrossRef]

11. Anuar Sharuddin, S.D.; Abnisa, F.; Wan Daud, W.M.A.; Aroua, M.K. A Review on Pyrolysis of Plastic Wastes. Energy Convers. Manag. 2016, 115, 308-326. [CrossRef]

12. Cheng, L.; Gu, J.; Wang, Y.; Zhang, J.; Yuan, H.; Chen, Y. Polyethylene High-Pressure Pyrolysis: Better Product Distribution and Process Mechanism Analysis. Chem. Eng. J. 2020, 385, 123866. [CrossRef]

13. Dhahak, A.; Grimmer, C.; Neumann, A.; Rüger, C.; Sklorz, M.; Streibel, T.; Zimmermann, R.; Mauviel, G.; Burkle-Vitzthum, V. Real Time Monitoring of Slow Pyrolysis of Polyethylene Terephthalate (PET) by Different Mass Spectrometric Techniques. Waste Manage. 2020, 106, 226-239. [CrossRef]

14. Singh, R.K.; Ruj, B.; Sadhukhan, A.K.; Gupta, P. Thermal Degradation of Waste Plastics under Non-Sweeping Atmosphere: Part 1: Effect of Temperature, Product Optimization, and Degradation Mechanism. J. Environ. Manag. 2019, 239, 395-406. [CrossRef]

15. Muhammad, C.; Onwudili, J.A.; Williams, P.T. Thermal Degradation of Real-World Waste Plastics and Simulated Mixed Plastics in a Two-Stage Pyrolysis-Catalysis Reactor for Fuel Production. Energ. Fuel. 2015, 29, 2601-2609. [CrossRef]

16. Knez, Ž.; Hrnčič, M.K.; Čolnik, M.; Škerget, M. Chemicals and Value Added Compounds from Biomass Using Sub- and Supercritical Water. J. Supercrit. Fluids 2018, 133, 591-602. [CrossRef]

17. Knez, Ž.; Markočič, E.; Hrnčič, M.K.; Ravber, M.; Škerget, M. High Pressure Water Reforming of Biomass for Energy and Chemicals: A Short Review. J. Supercrit. Fluids 2015, 96, 46-52. [CrossRef]

18. Pavlovič, I.; Knez, Ž.; Škerget, M. Hydrothermal Reactions of Agricultural and Food Processing Wastes in Sub- and Supercritical Water: A Review of Fundamentals, Mechanisms, and State of Research. J. Agric. Food Chem. 2013, 61, 8003-8025. [CrossRef] [PubMed]

19. Čolnik, M.; Knez, Ž.; Škerget, M. Sub- and Supercritical Water for Chemical Recycling of Polyethylene Terephthalate Waste. Chem. Eng. Sci. 2021, 233, 116389. [CrossRef]

20. Cata, A.; Miclau, M.; Ienascu, I.; Ursu, D.; Tanasie, C.; Stefanuta, M.N. Chemical Recycling of Polyethylene Terephthalate (PET) Waste Using Sub- and Supercritical Water. Rev. Roum. Chim 2015, 60, 579-585.

21. Sato, O.; Arai, K.; Shirai, M. Hydrolysis of Poly (Ethylene Terephthalate) and Poly (Ethylene 2,6-Naphthalene Dicarboxylate) Using Water at High Temperature: Effect of Proton on Low Ethylene Glycol Yield. Catal. Today 2006, 111, 297-301. [CrossRef]

22. Zhou, J.H.; Shen, G.Z.; Zhu, J.; Yuan, W.K. Terephthalic Acid Hydropurification over Pd/C Catalyst. In Studies in Surface Science and Catalysis; Rhee, H.-K., Nam, I.-S., Park, J.M., Eds.; New Developments and Application in Chemical Reaction Engineering; Elsevier: Amsterdam, The Netherlands, 2006; Volume 159, pp. 293-296.

23. Takebayashi, Y.; Sue, K.; Yoda, S.; Hakuta, Y.; Furuya, T. Solubility of Terephthalic Acid in Subcritical Water. J. Chem. Eng. Data 2012, 57, 1810-1816. [CrossRef]

24. Machado Cruz, R.; Boleslavská, T.; Beránek, J.; Tieger, E.; Twamley, B.; Santos-Martinez, M.J.; Dammer, O.; Tajber, L. Identification and Pharmaceutical Characterization of a New Itraconazole Terephthalic Acid Cocrystal. Pharmaceutics 2020, 12, 741. [CrossRef]

25. Muse, W.T.; Anthony, J.S.; Bergmann, J.D.; Burnett, D.C.; Crouse, C.L.; Gaviola, B.P.; Thomson, S.A. Chemical and Toxicological Evaluation of Pyrotechnically Disseminated Terephthalic Acid Smoke. Drug. Chem. Toxicol. 1997, 20, 293-302. [CrossRef]

26. Zhang, Y.M.; Sun, Y.Q.; Wang, Z.J.; Zhang, J. Degradation of Terephthalic Acid by a Newly Isolated Strain of Arthrobacter Sp.0574. S. Afr. J. Sci. 2013, 109, 1-4. [CrossRef]

27. PTA Production Capacity Globally 2023. Available online: https://www.statista.com/statistics/1065886/global-purifiedterephthalic-acid-production-capacity/ (accessed on 13 September 2021).

28. Diaz-Silvarrey, L.S.; McMahon, A.; Phan, A.N. Benzoic Acid Recovery via Waste Poly (Ethylene Terephthalate) (PET) Catalytic Pyrolysis Using Sulphated Zirconia Catalyst. J. Anal. Appl. Pyrolysis 2018, 134, 621-631. [CrossRef]

29. Del Olmo, A.; Calzada, J.; Nuñez, M. Benzoic Acid and Its Derivatives as Naturally Occurring Compounds in Foods and as Additives: Uses, Exposure, and Controversy. Crit. Rev. Food. Sci. Nutr. 2017, 57, 3084-3103. [CrossRef]

30. Indrayanto, G.; Syahrani, A.; Mugihardjo; Rahman, A.; Soeharjono; Tanudjojo, W.; Susanti, S.; Yuwono, M.; Ebel, S. Benzoic Acid In Analytical Profiles of Drug Substances and Excipients; Brittain, H.G., Ed.; Academic Press: Cambridge, MA, USA, 1999; Volume 26, pp. 1-46.

31. Benzoic Acid Market Size and Share, Analysis 2021-2027. Available online: https:/ /www.gminsights.com/industry-analysis/ benzoic-acid-market (accessed on 22 October 2021).

32. Benzoic Acid Global Market Volume 2015-2026. Available online: https://www.statista.com/statistics /1245227/benzoic-acidmarket-volume-worldwide/ (accessed on 22 October 2021).

33. Adschiri, T.; Sato, O.; Machida, K.; Saito, N.; Arai, K. Recovery of Terepthalic Acid by Decomposition of PET in Supercritical Water. Kagaku Kogaku Ronbunshu 1997, 23, 505-511. [CrossRef]

34. Lindquist, E.; Yang, Y. Degradation of Benzoic Acid and Its Derivatives in Subcritical Water. J. Chromatogr. A 2011, 1218, $2146-2152$. [CrossRef] [PubMed]

35. Palme, A.; Peterson, A.; de la Motte, H.; Theliander, H.; Brelid, H. Development of an Efficient Route for Combined Recycling of PET and Cotton from Mixed Fabrics. Text. Cloth. Sustain. 2017, 3, 1-9. [CrossRef] 
36. Chen, Z.; Hay, J.N.; Jenkins, M.J. The Thermal Analysis of Poly (Ethylene Terephthalate) by FTIR Spectroscopy. Thermochim. Acta 2013, 552, 123-130. [CrossRef]

37. Manatura, K.; Samaksaman, U. Characteristics and Combustion Kinetics of Fuel Pellets Composed of Waste of Polyethylene Terephthalate and Biomass. Glob. J. Environ. Sci. Manag. 2021, 7, 625-642. [CrossRef]

38. Hansen, E. Hazardous Substances in Plastic Materials 2013. Available online: https://www.byggemiljo.no/wp-content/uploads/ 2014/10/72_ta3017.pdf (accessed on 10 September 2021).

39. Khaneghah, A.M.; Limbo, S.; Shoeibi, S.; Mazinani, S. HPLC Study of Migration of Terephthalic Acid and Isophthalic Acid from PET Bottles into Edible Oils. J. Sci. Food Agric. 2014, 94, 2205-2209. [CrossRef]

40. Sandy, T.; Grady Jr, L.; Meininger, S.; Boe, R. Biological Treatment of 1,4-Dioxane in Wastewater from an Integrated Polyethylene Terephthalate (PET) Manufacturing. Proc. Water Environ. Fed. 2001, 2001, 88-117. [CrossRef] 